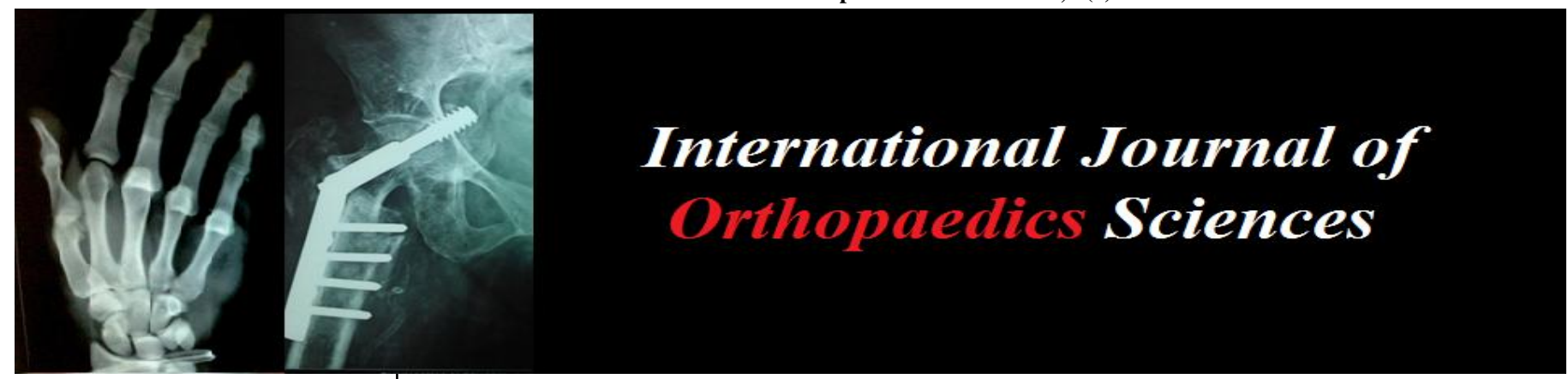

ISSN: $2395-1958$

IJOS 2017; 3(4): 540-543

(C) 2017 IJOS

www.orthopaper.com

Received: 13-08-2017

Accepted: 14-09-2017

Nitin Patil

Associate Professor, Department of Orthopaedics, Krishna

Institute of Medical Sciences

Deemed University, Karad,

Maharashtra, India

\section{Ketan Gupta}

Senior Resident, Department of Orthopaedics, Krishna Institute of Medical Sciences Deemed

University, Karad, Maharashtra, India

\section{Rupesh Go}

Junior Resident,

Department of Orthopaedics, Krishna Institute of Medical

Sciences Deemed University,

Karad, Maharashtra, India

\section{Rutvik Shah}

Junior Resident,

Department of Orthopaedics,

Krishna Institute of Medical

Sciences Deemed University,

Karad, Maharashtra, India

\section{Prashant Pandey}

Junior Resident, Department of Orthopaedics, Krishna Institute of Medical Sciences Deemed University, Karad, Maharashtra, India

\section{Amit Garud}

Junior Resident, Department of Orthopaedics, Krishna Institute of Medical Sciences Deemed University, Karad, Maharashtra, India
Correspondence

Rutvik Shah

Junior Resident,

Department of Orthopaedics,

Krishna Institute of Medical

Sciences Deemed University,

Karad, Maharashtra, India

\section{Role of flexible elastic nails in diaphyseal fractures of long bones of lower extremities in children of 5-14 years of age}

\author{
Nitin Patil, Ketan Gupta, Rupesh Gor, Rutvik Shah, Prashant Pandey and \\ Amit Garud
}

DOI: https://doi.org/10.22271/ortho.2017.v3.i4h.73

\begin{abstract}
Femoral and tibial fractures are common long-bone injuries in children. Above five years of age all such fractures, when treated conservatively could lead to loss of reduction, malunion, intolerance and complications associated with plaster. The goals are to stabilize the fracture, to control length and alignment. Flexible Elastic Nailing has become the choice of stabilization in paediatric long bone fractures. The aim of our study was to see the outcome of Flexible elastic nailing system in diaphyseal fractures of children of 5-14 years age. The study included total of 50 children treated with flexible elastic nailing system and they were followed up at 3,6,12 and 24 weeks. The average duration of callus formation was 3.8 weeks (4.2weeks in Tibia \& 3.4 weeks in femur). Radiological union was seen in a mean time of 9.65 weeks. Full weight bearing was possible in a mean time of 10 weeks. According to flynn's scoring criteria, excellent and satisfactory results were in $90 \%$ and $10 \%$ respectively. There were 2 cases of post-operative superficial infection which resolved with regular dressing and no cases of physeal injury and implant failure. Flexible elastic nail is a safe and satisfactory mode of treatment and is relatively easy to perform in disphyseal fracture of femur and tibia in children. It avoids the chances of physeal injury, infection and offers early mobilisation and rapid healing.
\end{abstract}

Keywords: Paediatric femur or tibia fractures, flexible elastic nailing, Flynn's criteria

\section{Introduction}

Femoral and tibial fractures are common long-bone injuries in children. The injuries are more common in boys, especially during the toddler years and early adolescence [1, 2]. The mechanism of injury varies from simple falls to high energy trauma ${ }^{[3]}$. Because of rapid healing and spontaneous correction of angulation most of the shaft fractures in children younger than Five years of age can be treated conservatively ${ }^{[4,5]}$. However management of fractures of long bones of lower extremity in growing children has been a subject of debate in paediatric orthopaedic community. In the past management of paediatric lower extremity fractures involved use of options like traction alone, early spica cast and traction followed by spica cast. Conservative treatment necessitates a long stay in hospital for traction and subsequent immobilization in an uncomfortable cast. This treatment is not well tolerated specially in adolescence ${ }^{[6]}$. Operative treatment results in shorter hospitalization and early mobilization, which has psychological, social, educational and economic advantages over conservative treatment. Above five years of age all such fractures, when treated nonoperatively could lead to loss of reduction, malunion, intolerance and complications associated with plaster. However, the best treatment between six and 16 years of age is a matter of debate ${ }^{[7]}$. Since the last two decades, there has been a growing tendency towards a more operative approach in patents over six years of age ${ }^{[8-10]}$. Between the age of 5 to 14 years, the available options for these fractures are: external fixation, flexible stable intramedullary nails, plate fixation, and locked intramedullary nailing. The goals are to stabilize the fracture, to control length, optimal alignment and early mobilisation. Excessive tissue dissection and tissue devitalisation is frequent during Open reduction internal fixation, which creates problems in wound healing and ultimately leading to infection, hence other less invasive methods were 
developed to treat fractures of tibia and femur ${ }^{[11]}$. Flexible Elastic Nailing, which is variously known as Elastic Stable Intramedullary Nailing, has become the choice of stabilization in paediatric long bone fractures ${ }^{[12,13]}$. Development of TENS has provided a simple, biocompatible, load bearing internal splint allowing early mobilization. As epiphyseal growth plate is not breeched, it avoids growth disturbance and has minimal risk of complications and has thus emerged as the most popular surgical modality for management of unstable paediatric lower extremity long bones fractures ${ }^{[14]}$.

\section{Materials and Methods}

In our study, 50 patients between age group of $5-14$ years having diaphyseal fracture of either femur or tibia were included. Patients less than 5 years of age, patients with pathological fractures, Compound Fractures, distal neurovascular deficit and any other fracture in ipsilateral limb were excluded.Routine investigations were done for all patients and operated under appropriate anaesthesia after prior informed consent. All patients were operated on radiolucent table under image intensifier guidance for visualizing reduction and verification of nail passage. Nails were inserted from proximal to distal for tibia and from distal to proximal for femur. Bone was exposed with a longitudinal incision. With the help of sharp awl, entry was made through the cortex to obtain access to the medullary cavity. Care was taken to ensure that growth plate was not breached while making the entry point. Nails were bent prior to insertion so that apex of both nail rest at fracture site and were inserted using $\mathrm{T}$ handle. Once fracture site was reached, fracture was manipulated under image intensifier guidance to obtain reduction and nails were passed further upto metaphysis and adequate three point fixation was ensured with tip of nails facing in opposite directions. All patients received antibiotic 30 mins prior to the surgery and on the $1^{\text {st }}$ post-operative day. Thigh spica Cast was given to all patients operated for Femur Fracture and below Knee slab to all patients Operated for Tibia Fracture. On post-operative day 1, gradual movements at hip and knee were started and patients were encouraged to do non weight bearing walking with the help of walker. The patients were followed up at intervals of 3,6,12,24 weeks and were evaluated clinically as well as radiologically for union and callus formation. At 24 weeks follow up final evaluation was done by using Flynn criteria.

Table 1: Flynn's scoring criteria

\begin{tabular}{|c|c|c|c|}
\hline Variables & Excellent & Satisfactory & Poor \\
\hline Limb-length inequality & $<1.0 \mathrm{~cm}$ & $<2.0 \mathrm{~cm}$ & $>2.0 \mathrm{~cm}$ \\
\hline Malalignment & 5 degrees & 10 degrees & $>10$ degrees \\
\hline Unresolved pain & Absent & Absent & Present \\
\hline Other complications & None & Minor and resolved & Major and lasting morbidity \\
\hline
\end{tabular}

\section{Results}

In our study there were 32 boys (64\%) and 18 girls (36\%). Minimum age was 5 years and maximum age was 14 years while most fractures occurred between 8 to 11 years $(56 \%)$. Major cause of fracture was road traffic accident in $76 \%$ cases followed by fall from height in $24 \%$ cases. Out of 50 fractures, there were $60 \%$ tibia fractures and $40 \%$ femur fractures. Right side was more commonly involved $(68 \%)$. Majority of patients (44\%) had oblique fracture pattern followed by transverse pattern $(38 \%)$. In our study, $84 \%$ of patients were operated on the next day of admission and average duration of hospital stay was 6 days. Gradual range of movements at hip and knee joint were initiated on $1^{\text {st }}$ postoperative day.

Partial weight bearing was started ones the splint (Thigh spica cast or Below knee slab) was removed. In $70 \%$ cases splint was removed on $6 \mathrm{wks}$ post-operative; in $26 \%$ cases early weight bearing (4 wks) was started due to good callus formation radiologically but in $4 \%$ cases delayed weight bearing ( 9 weeks) was done. We noticed patients in whom early weight bearing was started were between 5 to 8 years of age. Full weight bearing was started in $96 \%$ cases at 10 weeks post operatively and in remaining $4 \%$ cases, it was started at 13 weeks.

In our study, average duration for complete range of movement at hip and knee was 5 days post operatively and once patient achieved full range of movement, they were discharged.

In our study, at 24 weeks follow up 90\% patients had shortening less than $1 \mathrm{~cm}, 8 \%$ patients had shortening between $1-2 \mathrm{~cm}$ and $2 \%$ patient had shortening of $2.5 \mathrm{~cm} .94 \%$ of patients had angulations less than $5^{\circ}$ while remaining $6 \%$ had angulation between $5-10^{\circ}$. Two patients had superficial infection which were resolved with regular dressing. None of the patients had pain at operative site.

Table 2: Showing the results of flynn's scoring criteria

\begin{tabular}{|c|c|c|}
\hline Results & Number of cases & \\
\hline & Tibia & Femur \\
\hline Excellent & $23(92 \%)$ & $22(88 \%)$ \\
\hline Good & $2(8 \%)$ & $3(12 \%)$ \\
\hline Poor & $0(0 \%)$ & $0(0 \%)$ \\
\hline
\end{tabular}

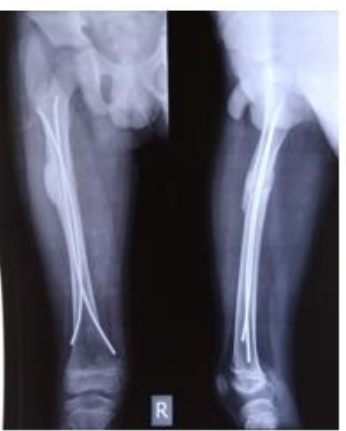

(d) 12 weeks

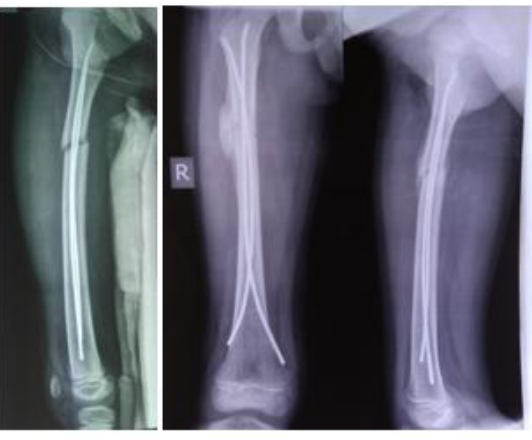

(c) 6 weeks

$\sim 541 \sim$

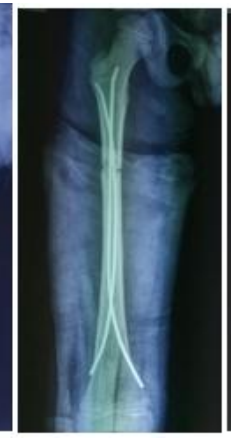

(b) Post-operative 

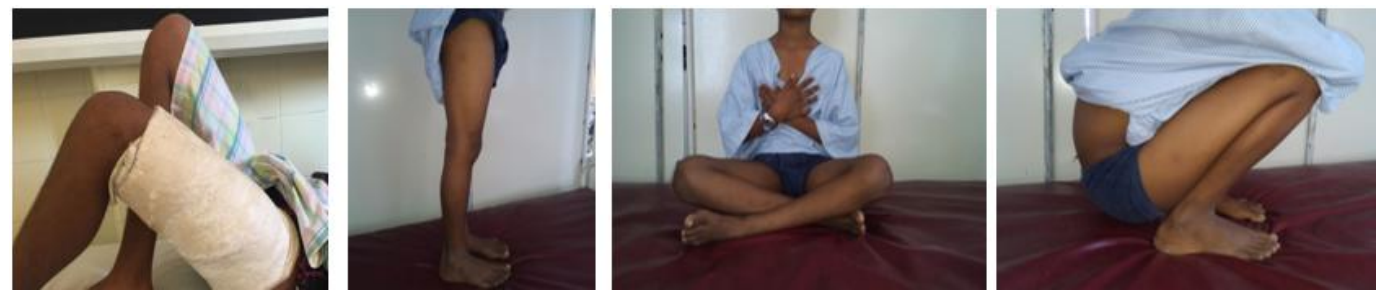

Fig 1: Series of femur fracture treated with elastic nailing

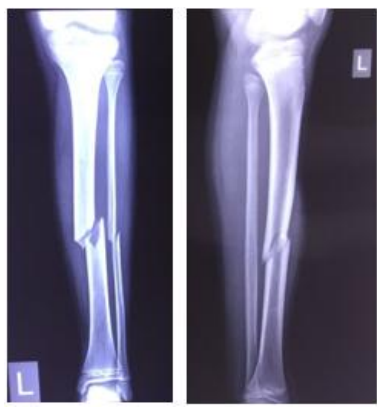

(a) Pre-operative

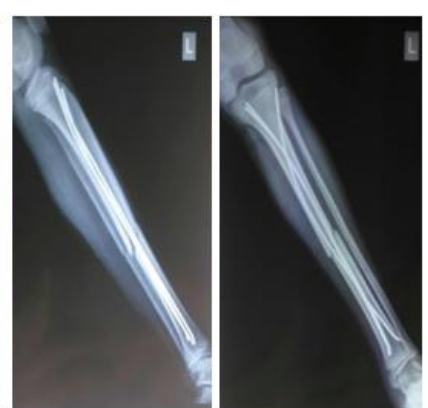

(b) Post-operative

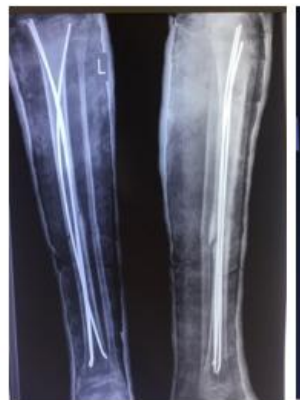

(c) 6 weeks

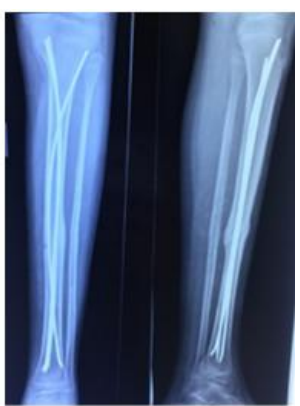

(d) 12 weeks
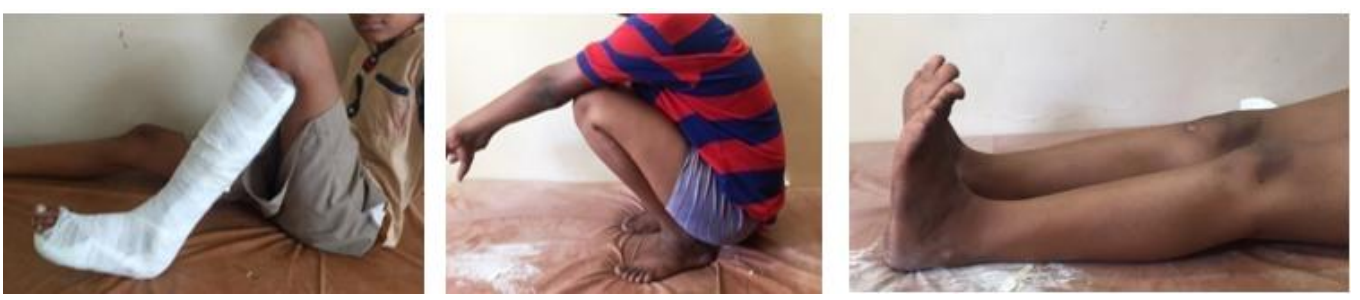

Fig 2: Series of tibia fracture treated with elastic nailing

\section{Discussion}

Surgical management of long bones of lower extremity in paediatric age group has been controversial. Multiple treatment options have been tried over past two to three decades. All treatment options were found to be associated with some complications. Multiple options like traction, hip spica, compression plates, external fixation, flexible/elastic stable intramedullary nail exist for treatment in age group of 5 -14 years. Plate osteosynthesis is widely used but associated with large exposure, relative longer duration of immobilisation, risks of delayed union, infection and large dissection for plate removal ${ }^{[15,16]}$. Use of interlocking nails in skeletally immature children has reported complications like avascular necrosis of femoral head, coxa valga ${ }^{[17,18]}$. External fixation has advantage of good stability and early mobilization but associated with problems of pin tract infections and refractures through tracts ${ }^{[19,20]}$. Flexible elastic nail acts as load sharing device, allowing early mobilization, not disrupting blood supply of epiphyseal growth plates, maintaining limb length and alignment, hence ideal implant for treatment of paediatric lower extremity long bone fractures ${ }^{[21-23]}$. It is based upon the principle of three point fixation that works by balancing forces between two opposing flexible implants. This balance is attained by using a nail diameter of $40 \%$ of narrowest canal diameter leading to a double-C construct. In our study majority of cases had excellent or satisfactory results which is comparable to series reported by Pulate et al ${ }^{[24]}$ results were excellent in $60 \%$, successful in 35\% and poor in 5\% and Moroz et al ${ }^{[25]}$ was excellent in $65 \%$, satisfactory in $25 \%$, and poor in $10 \%$. In our study, duration of hospital stay was between 5 to 12 days where as in a study conducted by Houshian et al ${ }^{[26]}$. The mean hospital stay was six days and range of hospital stay was 2 to 20 days. Two cases had minor complication of superficial wound infection which was healed after regular dressing. In study conducted by Khazzam et al ${ }^{[27]}$. there were 14 complications, three re-fractures, two delayed unions, three varus or valgus malalignment, five nail-tip irritations, and one asymptomatic proximal nail migration.

\section{Conclusion}

Flexible elastic nail is simple, reliable and effective method for management of lower extremity long bone fractures in paediatric age as it takes short operative time, minimal blood loss, small operative scar, shorter hospital stay, early mobilisation and minimum complications.

\section{References}

1. Hedlund R, Lindgren U. The incidence of femoral shaft fractures in children and adolescents. J Pediatr Orthop. 1986; 6:47-50.

2. Flynn JM, Skaggs DL. Chapter 22: Femoral Shaft Fractures. In: Kasser J, Beaty J editor(s). Rockwood and Wilkins' Fractures in Children. Philadelphia: Lippincott Williams \& Wilkins 2010, 809-815.

3. Bridgman S, Wilson R. Epidemiology of femoral fractures in children in the West Midlands region of England 1991 to 2001. J Bone Joint Surg Brit. 2004; 86:1152-7

4. Buckley SL. Current trends in the treatment of femoral shaft fractures in children and adolescents. Clin Orthop Relat Res. 1997; 338:60-73.

5. Gwyn DT, Olney BW, Dart BR, Czuwala PJ. Rotational control of various pediatric femur fractures stabilized with Titanium Elastic Nails. J Pediatr Orthop. 2004; 24:172-7.

6. Metaizeau JP. Stable elastic intramedullary nailing for fracture of the femur in children. J Bone Joint Surg (Br.). 
2004; 86-B:954-957

7. Flynn JM, Luedtke LM, Theodore J, Ganley TJ, Dawson $\mathrm{J}$, Davidson RS et al. Comparison of titanium elastic nails with traction and a spica cast to treat femoral fractures in children. J Bone Joint Surg Am. 2004; 86:770-7.

8. Narayanan UG, Hyman JE, Wainwright AM, Rang M, Alman BA. Complications of elastic stable intramedullary nail fixation of pediatric femoral fractures and How to avoid them. J Pediatr Orthop. 2004; 24:3639.

9. Metaizeau JP. Stable elastic nailing for fractures of the femur in children. J Bone Joint Surg Br. 2004; 86:954-7.

10. Canale ST, Tolo VT. Fractures of the femur in children. J Bone Joint Surg Am. 1995; 77:294-31.

11. Mihir R Solanki. A comparative study of plating versus nailing in distal tibia metaphyseal fracture. IJOS. 2017; 3(2):86-89.

12. Bhaskar A. Treatment of long bone fractures in children by flexible titanium nails. Indian J Orthop. 2005; 39:1668.

13. Sanders JO, Browne RH, Mooney JF, Raney EM, Horn BD, Anderson DJ et al. Treatment of femoral shaft by pediatricorthopedist: Results of a 1998 survey. J Pediatr Orthop. 2001; 21:436-41.

14. Flynn JM, Hresko T, Reynolds RA. Titanium elastic nails for paediatric femur fractures: A multi-center study of early results with analysis of complications. J Pediatr Orthop. 2001; 21:4-8.

15. Reeves RB, Ballard RI, Hughes JL, Jackson. Internal fixation versus traction and casting of adolescent femoral shaft fractures. J Pediatr Orthop. 1990; 10(5):592-5

16. Ward WT, Levy J, Kaye A. Compression plating for child and adolescent femur fractures. J Paediatr Orthop. 1992; 12(5):626-32.

17. Beaty JH, Austin SM, Warner WC. Interlocking intramedullary nailing of femoral-shaft fractures in adolescents: Preliminary results and complications. J Pediatr Orthop. 1994; 14(2):178-83.

18. Letts M, Jarvis J, Lawton L, Davidson D. Complications of rigid intramedullary rodding of femoral shaft fractures in children. J Trauma. 2002; 52(3):504-16.

19. Aronson J, Tursky EA. External fixation of femur fractures in children. J Pediatr Orthop. 1992; 12(2):15763.

20. Krettek C, Haas N, Walker J, Tscherne H. Treatment of femoral shaft fractures in children by external fixation. Injury. 1991; 22(4):263-66.

21. Gamal E, Mohamed MF, Mohamed AK, Ahmed E. Titanium elastic nail fixation for paediatric femoral and tibial fractures. Acta Orthop. Belg. 2009; 75:512-520.

22. Flynn JM, Skaggs DL, Sponseller PD, Ganley TJ, Kay RM, Kellie Leitch KK. The operative management of pediatric fractures of the lower extremity. J Bone Joint SurgAmer. 2002; 84:2288-300.

23. Saikia KC, Bhuyan SK, Bhattacharya TD, Saikia SP. Titanium elastic nailing in femoral diaphyseal fractures of children in 6-16 years of age. Indian J Orthopaed. 2007; 41:381-5

24. Pulate A, Jadhav A, Shah BN. Study of the outcome of titanium elastic nail system in diaphyseal femoral fractures in children. MOA Journal. 2012; 7(3):6-8.

25. Moroz LA, Launay F, Kocher MS, Newton PO, Frick SL, Sponseller PD et al. Titanium elastic nailing of fractures of the femur in children. JBJS. 2006; 88(10):1361-6.

26. Houshian S, Gothgen CB, Pedersen NW. Femoral shaft fractures in children. Acta Orthop Scand. 2004; 75(3):24951.

27. Khazzam M, Tassone C, Liu XC, Lyon R, Freeto B, Schwab $\mathrm{J}$ et al. Use of Flexible Intramedullary Nail Fixation in Treating Femur Fractures in Children. Am J Orthop. 2009; 38(3):49-55. 